\title{
The Informational Content And Valuation Ramifications Of Earnings Restatements
}

\author{
James E. Owers, (E-mail: jowers@gsu.edu), Georgia State University and Harvard University \\ Chen-Miao Lin, Georgia State University \\ Ronald C. Rogers, University of South Carolina
}

\begin{abstract}
This paper analyzes the market responses to different categories of accounting restatements. Accounting restatements have been occurring with increasing frequency in recent years, generating significant discussion as to their causes and consequences. We examine both of these dimensions of restatements. We identify 9 categories into which restatements can be classified. When examining their valuation consequences, we find statistically significant negative revaluations for the overall sample. However, there is substantial variation in valuation changes across the various categories of restatements. Investors react the most negatively to restatements resulting from accounting issues (i.e. errors/irregularities/method-changes). This is greatly magnified when there is a contemporaneous change in the firm's CEO. At the other end of the spectrum, we find positive reactions to restatements that reflect and provide the accounting calibration of previously announced settlements of legal issues. A notable feature of the findings is that for some categories there are valuation changes in response to accounting restatements which are seemingly just recording the implications of previously announced corporate happenings. In the context of efficient market perspectives, some of these changes at the time of the restatement announcement itself are somewhat surprising.
\end{abstract}

\section{Introduction}

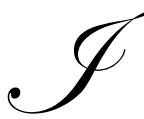

$\mathrm{n}$ recent years, the number of restatements of previously announced accounting data has reached new levels. This heightened restatement activity has received increasing attention both as to its causes and consequences. The purpose of this paper is to systematically examine these dimensions of recent accounting restatements. It transpires that there are several reasons for accounting restatements, and the informational content, and associated revaluations, vary notably across categories.

There has been considerable speculation regarding the reasons for this increased level of restatements of previously announced accounting data. These include the possibility of increasing pressure on management to deliver the results markets expect and demand. However, the financial issues associated with restatements are distinct from the set of factors associated with numerous research investigations into analysts' forecasts. The announcement of ex-poste results supposedly resolves the uncertainty surrounding ax-ante anticipations and the estimates within that informational content undertaken by external analysts. It seems an extreme measure to intentionally announce overstated results as delivered, given the checks and balances on such practices as auditing (both internal and external) and subsequent accounting statements which might well reveal prior mischief. While intentional fraud is part of the reasons for restatements, we document that it is not a major or dominant category.

The high frequency of restatements reported in the press have led to heightened concern by the SEC and investors. The SEC has recently announced an investigation into the recent level of restatements, and the selfregulating role of the accounting profession is reminded of the potential constraints and discipline provided by the governmental regulatory process. Financial markets are obviously perturbed by the dissemination of accounting

Readers with comments or questions are encouraged to contact the authors via email. 
data subsequently revealed to be erroneous. The "reporting and stewardship" role of accounting clearly presumes that announced ex-poste accounting data resolves prior uncertainty pertaining to "analysts' estimates", subject of course to the perspectives of perceived "quality of earnings" being applied in the interpretation of how individual firms apply the discretion embedded within the application of GAAP.

In this study we identify nine categories of restatements according to the reason provided for their necessity. These nine categories emerged after detailed analysis of restatements and are as follows: (1) accounting issues (errors/irregularities/method- change); (2) SEC initiated; (3) acknowledged fraud; (4) earnings/loss arrangement; (5) resulting from a restructuring or spin-off; (6) associated with a legal settlement; (7) merger or joint venture related; (8) caused by a stock split/dividend; (9) reason not determined.

We then examine the market response for the identified different reasons. Our analysis shows that the mean abnormal returns (prediction errors) are statistically significantly negative for the overall sample. When we look at different categories we find that the market responds most negatively toward restatements resulting from accounting issues, especially when accompanied by an associated CEO resignation. In this context, the negative prediction errors are about 3 times greater than for the overall sample. The legal settlement is the only category with positive prediction errors and also has the highest proportion of positive observation. Typically, the settlement is announced before the restatement. Another notable finding is that restatements undertaken in order to confirm with the SEC's concerns are the category with the second smallest negative mean prediction errors. The negative reactions in such circumstances are approximately $1 / 3$ to $1 / 2$ of those of the overall sample.

The paper is organized as follows. The next section reviews the regulatory context and literature. Section 3 outlines the sample selection procedures and describes the sample. Section 4 details the event study methodology and Section 5 presents the findings. The paper ends with a summary in the final section.

\section{The Regulatory Context and Literature Review}

Regulatory Guidelines: Guidelines for addressing circumstances requiring accounting restatements come from both the SEC and the Accounting professional guidelines.

The SEC requires managers to make prompt disclosure of material facts when the earlier statements no longer have a reasonable basis. Specifically, the SEC states that "there is a duty to correct statements made in any filing, whether or not the filing is related to a specified transaction or event, if the statements either have become inaccurate by virtue of subsequent events, or are later discovered to have been false and misleading from the outset, and the issuer knows or should know that persons are continuing to rely on all or any material portion of the statements." (SEC Accounting Rule No. 6084, SEC Docket 1048, 1979).

The criteria for restatement of prior period's interim financial statements are set forth in Statement of Financial Accounting Standards No. 16. It indicates that "Interim prior period restatement is restricted to material nonrecurring adjustments or settlements of litigation or similar claims, income taxes, re-negotiation proceedings, or utility revenue under the rate-making process." Accounting series Release No. 177 also requires that "the registrant shall provide a narrative analysis of the results of operations explaining the reasons for material changes in the amount of revenue and expense items...."

Literature: An important and foundational work in the restatement literature is that of Kinney and McDaniel (1989) who examined the characteristics of firms that correct previously reported quarterly earnings. In addition to typically negative reactions at the time of the restatement, Kinney and McDaniel also find negative abnormal returns between the issuance of erroneous quarterly reports and corrections.

They find that firms making corrections are typically smaller, less profitable, more highly leveraged, slower growing, and received more qualified audit opinions than other firms in the same industry. They attribute this to circumstances whereby small companies have weak controls and thus have higher probability of occurrence of material errors. The findings of Kreutzfeldt and Wallace (1986) confirm that small firms have more errors than large firms, 
and that these errors tend to be larger in amount. However, Willingham and Wright (1985) report that no empirical association between errors detected by the audit process and firm size.

DeFond and Jiambalvo (1991) confirm that earnings overstatements are negatively correlated with the growth in earnings. They also show that overstatements appear more often in those firms that have diffuse ownership, have lower growth in earnings and relatively fewer income-increasing GAAP alternatives available, and are less likely to have audit committees.

Kinney and McDaniel (1993) found significant increases in audit delay for firms correcting previously reported interim earnings. They explain that audit delay is expected because the restatement may be the result of client factors such as poor internal controls or intentional violation of the securities acts by client management. The presence of these factors will increase audit work. They further indicate that the increased audit delay is due to addressing circumstances associated with those firms with declining earnings who overstate the previously reported interim earnings.

Restatements are often associated with litigation against the firm's management and their auditors. ${ }^{i}$ The managers are sued because of misleading the investors or the intent to deceive. According to Section 10b of SEC Rule 10b-5 it is unlawful for managers to make an "untrue statement of a material fact or to omit to state a material fact necessary in order to make the statements made, in light of the circumstances in which they were made, not misleading". Francis et. al. (1994) note that "in a typical 10b-5 case plaintiffs allege they bough stock at inflated prices because managers misled the market by disseminating overly optimistic information or by failing to disclose material adverse information". Kellogg (1984) finds that courts are more likely to enforce penalties on misstatement lawsuits. As for third party responsibility, according to SAS 53, the auditor's responsibility is to "design the audit to provide reasonable assurance of detecting errors and irregularities that are material to the financial statements". Thus, auditors face litigation either for not detecting the misstatements or not disclosing and correcting the misstatements. Litigation against auditors will have consequences for them in terms of loss in reputation for competence, and independence. For examination of these issues, see Benston (1975), and Palmrose (1988). Bonner, Palmrose, and Young (1998) document that more frequent frauds and fictitious transaction frauds are related to the likelihood of litigation against auditors. St. Pierre and Anderson (1984) also show that auditors are often sued for earnings overstatements.

It is also common to find auditor changes or auditor resignations around the time of the announcement of an accounting restatement. Fraud is one of the reasons of restatement and the likelihood of fraud increases the probability that the auditor resigns (Bockus and Gigler, [1995]). Moreover, the litigation risk usually associated with restatements leads auditors to adjust their client portfolios and resign from engagements in which they perceive high potential for litigation (Brumfield et al, [1983]; Siliciano [1988]; Sullivan, [1992]; Krishnan and Krishnan, [1997]).

Pratt and Stice (1994) also note that a client's overall financial condition is crucial for auditors to assess litigation risk. Stice (1991) and Lys and Watts (1994) indicate that client financial distress affects the likelihood of erroneous financial statements being issued and is positively related to lawsuits against auditors. As previously noted, Kinney and McDaniel (1989) as also DeFond and Jiambalvo (1991), found that the firms making restatements are generally smaller and less profitable firms. Thus their financial condition might be a reason that contributes to auditor resignations. From a firm's perspective, it might "search for an auditor willing to support a proposed accounting treatment designed to help a company achieve its reporting objectives even though that treatment might frustrate reliable reporting" (Securities and Exchange Commission, 1988). As an obvious illustrative context, lower accounting earnings can contribute to firms violating debt covenants. The possibility of violation will motivate firms to prefer income-increasing accounting procedures rather than the procedures deemed appropriate and proposed by auditors. This set of circumstances profiles the most frequent auditor-client disagreements reported in 8-Ks (DeFond and Jiambalvo, 1993).

Since accounting errors and irregularities are the main cause of restatements, the accounting procedures disputes between firms and auditors could be the main reason leading to auditor changes. DeFond and Jiambalvo (1993) also indicate that firms having disagreements with auditors are more likely to have higher leverage and a de- 
cline in earnings, which are also the characteristics of restatement firms reported by Kinney and McDaniel (1989). Therefore, it is not too surprising that auditor changes or auditor resignations are frequently associated with restatements.

Restatement need not be completely negative for firms. Meeks (1992) points out that the restatements, in some cases, alter the information set publicly available about a security, and in other cases, alter variables specified in loan or salary contracts. The SEC is also concerned about restatements caused by restructurings. "Investors love restructurings because, following a jumbo charge against earnings, a company's profit nearly always improves sharply. That is because lots of companies write off certain expenses all at once that would otherwise be a drag to earnings over a longer period" (The Wall Street Journal, Nov. 2, 1994). The announcement of restructuring has a "cathartic effect" (The Wall Street Journal, Mar. 22, 1994).

In the context of the prior research on accounting restatements profiled above, this paper investigates the valuation consequences of restatements during the interval 1994-1997, according to the cause of and context for the restatement.

\section{Sample selection and description}

The preliminary sample of restatement of previously issued financial statements was drawn from The Wall Street Journal. A text search was employed. First we used the key words restat? (Which including restate, restates, restated, restating, restatement, and restatements), to search The Wall Street Journal to find the related news from 1994 to 1997. Then announcement and outcome dates were identified from The Wall Street Journal and Lexis/Nexis. Firms are included in the sample only when the restatement announcement dates can be determined unambiguously, and are not confounded by contemporaneous new information regarding the firm's prospects.

Several filters were employed to ensure only genuine restatements during the sample years were included. References to restatements in prior fiscal years were eliminated first, because the restated results were mentioned just for comparison of the recent quarter results. In some instances, the announcement dates either could not be determined, or the related news has appeared in the year-earlier search.

Other reasons for eliminating restatement firms from the sample fell into the following categories: (1) firms with announcement of restatement being confounded with new quarter earnings results. However, if a firm just announced that the expected earnings would be better or worse than previous quarter without any particular quantification amount of earnings being released, the firm was included in the sample, but assigned to another restatement category (as described below). (2) The firm was not listed on the CRSP daily stock master file at the time of restatement announcement. (3) Firms whose returns series on the CRSP daily stock return file ended prior to the date of the restatement announcement. After application of the above filters, an empirical sample of 173 firms from 1994 to 1997 resulted. Table 1 provides descriptive details of the sample.

According to the reason for the restatement, we classified the sample into the following categories:

1. Accounting "issues": Specifically accounting errors/irregularities/method-change. Initially we sought to separate this category into the three indicated subsets, but for some firms we found that classifying them into one of these three subsets became somewhat arbitrary, and thus we combined these three reasons into one category.

2. SEC related. These restatements involved a SEC investigation, or circumstances where the SEC disagreed the treatment of some accounting procedure between the period of the announcement and outcome of restatement.

3. Fraud.

4. Earnings/loss transfer. This involved a rearrangement of earnings (or loss) from one quarter to another.

5. Associated with a restructuring/spin-off.

6. Legal context: resulting from the settlement of lawsuits.

7. Merger or joint venture related.

8. Associated with a stock split/dividend: restatement was caused by stock split or stock dividend issued. 
9. $\quad$ Reason not determined.

Table 1

Sample description

\begin{tabular}{|c|c|c|c|c|c|}
\hline $\begin{array}{ll}\text { Reason } & \text { Year } \\
\end{array}$ & 1994 & 1995 & 1996 & 1997 & Total \\
\hline $\begin{array}{l}\text { Accounting errors/ irregulari- } \\
\text { ties/method change }\end{array}$ & 23 & 25 & 27 & 19 & 94 \\
\hline $\begin{array}{l}\text { Accounting reason } \\
\text { confounded with CEO resign }\end{array}$ & 5 & 2 & 7 & 0 & 14 \\
\hline $\begin{array}{l}\text { Accounting reason } \\
\text { confounded with expected earnings } \\
\text { announcement }\end{array}$ & 1 & 1 & 1 & 0 & 3 \\
\hline SEC involved & 7 & 2 & 1 & 3 & 13 \\
\hline $\begin{array}{l}\text { SEC involved confounded with CEO } \\
\text { resigned }\end{array}$ & 2 & 0 & 0 & 0 & 2 \\
\hline Fraud & 1 & 0 & 1 & 2 & 4 \\
\hline Earnings/loss arrangement & 1 & 0 & 0 & 0 & 1 \\
\hline Restructuring/spin-off & 2 & 3 & 5 & 5 & 15 \\
\hline $\begin{array}{l}\text { Restructuring confounded with ex- } \\
\text { pected earnings announcement }\end{array}$ & 0 & 1 & 1 & 0 & 2 \\
\hline Legal settlement & 0 & 4 & 0 & 1 & 5 \\
\hline $\begin{array}{l}\text { Settlement and restatement an- } \\
\text { nounced simultaneously }\end{array}$ & 2 & 2 & 2 & 2 & 8 \\
\hline Merger or joint venture related & 3 & 1 & 2 & 1 & 7 \\
\hline $\begin{array}{l}\text { Merger and restatement announced } \\
\text { simultaneously }\end{array}$ & 0 & 0 & 1 & 0 & 1 \\
\hline Stock split/dividend & 1 & 0 & 0 & 0 & 1 \\
\hline Reason not determinant & 1 & 0 & 0 & 2 & 3 \\
\hline Total & 49 & 41 & 48 & 35 & 173 \\
\hline
\end{tabular}

Note (a): Announced to be expected better/worse earnings, without amounts of earnings quantified.

In some instances there was a basis for classifying restatements into more than one of the above 9 categories. If the restatement reason includes both another reason and SEC involved, the SEC category was assigned. In many instances the restatement announcement was accompanied by the announced resignation of the firm's $\mathrm{CEO} /$ President. In these instances, we assigned the restatement to one of the 9 categories identified based on other stated caused for the resignation. However, the significance of a CEO/President resignation is such that in some instances (for example with accounting errors/irregularities/method change) we investigate the separate effect of this attribute of a restatement announcement.

The frequency of occurrence of the categories, and the inter-temporal distribution of the 173 sample restatements is detailed in Table 1.

\section{Empirical methods}

The event-time methods we use are described by Dodd and Warner (1983), and Hite and Owers (1983). For each security $j$ we estimate the market model and compute an excess return, or prediction error (PE), for period $t$ as

$$
P E_{j t}=R_{j t}-\left(a_{j}+b_{j} R_{m t}\right)
$$

where $R_{j t}$ is the return on security $j$ for period $t, R_{m t}$ is the rate of return for period $t$ on the equal-weighted CRSP index, and $a_{j}$ and $b_{j}$ are the ordinary least squares estimates of the coefficients of the market model regression for firm $j$. With daily data the parameters are estimated from day -200 to day -51 in relation to the announcement on 
day 0 .

The Dodd-Warner procedure calls for standardizing each prediction error by the estimate of its standard error. The standardized prediction error is computed as

$\mathrm{SPE}_{\mathrm{jt}}=\mathrm{PE}_{\mathrm{jt}} / \mathrm{s}_{\mathrm{jt}}$

where $s_{j t}$ is the standard error of the forecast for security $j$ for period $t$. Under the null hypothesis of no prediction errors, the prediction errors are assumed to be normally distributed with a mean of zero, so the standardized prediction errors are assumed to be $t$-distributed. Furthermore, we assume the standardized prediction errors are serially and cross-sectionally independent.

To measure prediction errors over a specific interval for firm $j$ we sum the prediction errors to give the cumulative prediction error, i.e.,

$$
\mathrm{CPE}_{\mathrm{j}}=\sum_{\mathrm{t}=\mathrm{T}_{1 \mathrm{j}}}^{\mathrm{T}_{2 \mathrm{j}}} \mathrm{PE}_{\mathrm{jt}} \text {, }
$$

where $\mathrm{T}_{1 j}$ and $\mathrm{T}_{2 j}$ are firm-specific event dates (e.g., the press and outcome dates). For a sample of $N$ securities the mean cumulative prediction error is given by

$$
\overline{\mathrm{CPE}_{j}}=\sum_{j=1}^{\mathrm{N}} \mathrm{CPE}_{j} / \mathrm{N}
$$

To form the interval test statistic, we first standardize the individual $S P E_{j}$ for the number of days in the interval for firm $j$ as

For the overall sample the interval test statistic is given by

$$
\operatorname{SCPE}_{j}=\sum_{\mathrm{t}=\mathrm{T}_{1 \mathrm{j}}}^{\mathrm{T}_{2 \mathrm{j}}} \mathrm{SPE}_{\mathrm{jt}} / \sqrt{\mathrm{T}_{2 \mathrm{j}}-\mathrm{T}_{1 \mathrm{j}}+1} .
$$

$\mathrm{Z}=\sum_{\mathrm{j}=1}^{\mathrm{N}} \mathrm{SCPE}_{\mathrm{j}} / \sqrt{\mathrm{N}}$

Since the individual $S P E_{j t} \mathrm{~s}$ are assumed to be unit-normal and independent under the null hypothesis of no prediction errors, both $S C P E_{j}$ and $Z$ will be approximately unit-normal.

\section{Results: The Valuation Consequences of Restatements}

\section{Overall Sample}

Table 2 summarizes the stock price reactions around the restatement announcements for the overall sample. The table shows daily cumulative prediction errors (CPEs), the test statistics, and the proportion of positive cumulative prediction errors for the sample of restatements for intervals from 10 days before the restatement announcement (day 0 ) through 1 day after the outcome is revealed (day $\mathrm{T}$ ). The interval denoted ' $-2, \mathrm{~T}+1$ ' presents all trading days from 2 days before the first restatement announcement through 1 day after the outcome ("resolution") announcement. In some instances, the first announcement (the "press date") did not provide all information pertaining to the restatement. In such cases, the additional resolution of uncertainty takes place at the "outcome/resolution" date.

Overall sample mean cumulative prediction errors (CPEs) for various intervals from 10 days before the announcement (day 0) through 1 day after the outcome is revealed (day T) for a sample of restatement from 1994 to 
1997.

Table 2: Overall sample

\begin{tabular}{|c|c|c|c|c|}
\hline Interval & $\mathbf{N}$ & Mean CPEs & $\mathbf{Z}$ & Proportion of positive observation \\
\hline$-10,0$ & 173 & -.12676 & -13.825 & 33.53 \\
\hline$-5,0$ & 173 & -.12008 & -18.375 & 27.75 \\
\hline$-1,0$ & 173 & -.08768 & -23.862 & 30.06 \\
\hline$-2, \mathrm{~T}+1$ & 33 & -.29766 & -9.446 & 18.18 \\
\hline
\end{tabular}

For the overall sample, Table 2 reports that the average prediction errors over $(-10,0)$ are $-12.68 \%$, which is strongly statistically significant $(Z=-13.825)$. This significant decrease in value is concentrated around the 2-day announcement window $(-1,0)$. There the CPE is $-8.77 \%(Z=-23.86)$. For restatements where two announcements (the "Press" and "Resolution" dates, respectively) were made, the decline in value does not end with the initial restatement announcement. The mean prediction errors from day -2 to day $T+1$ increases to $-29.77 \%(Z=-9.45)$. Thus, significant negative prediction errors are detected between the initial restatement announcement and resolution announcement. Note that there are 33 observations in the $(-2, T+1)$ interval because only these 33 observations have two distinct "Press" announcement and "Resolution" outcome dates.

Not surprisingly, restatements have primarily negative valuation consequences. For intervals ending with the initial announcement, approximately $30 \%$ of the observations have positive prediction errors, but for the ($2, \mathrm{~T}+1$ ) interval only $18.18 \%$ of the observations have positive prediction errors.

Within this context of overall significant negative reactions to restatement announcements, the following subsections discuss (and Table 3 through Table 8 present) the mean cumulative prediction errors for each category with more than three observations.

\section{Accounting Issues}

The findings for restatements associated with the accounting issues (i.e. errors/irregularities/method change) category are reported in Table 3 . The mean prediction errors are $-8.44 \%(\mathrm{Z}=-18.18)$ at the immediate restatement announcement interval $(-1,0)$ and only $27.66 \%$ of the restatements were associated with positive prediction errors. Not surprisingly, since 54\% (94/173) of the observations fells in this accounting category, the magnitude of the mean cumulative prediction error here is close to that of the overall sample.

For accounting errors/irregularities/method-change restatements associated with a CEO resignation $(\mathrm{n}=$ 14), Table 3a reports that the mean cumulative prediction errors over $(-5,0)$ are $-31.76 \%(Z=-12.17)$, and $-22.28 \%$ $(\mathrm{Z}=-14.83)$ at the immediate restatement announcement $(-1,0)$. These negative prediction errors have a magnitude that is approximately 3 times that of the overall accounting issues category, and this is the category with the highest negative mean prediction errors among all categories. The mean prediction errors for the $(-2, \mathrm{~T}+1)$ interval is $48.73 \%$. The test statistic for this magnitude is relatively small because of only 5 firms having separate announcements, and the length of the intervals between those announcements. Nevertheless, it is notable that firms restating earning because of accounting issues and simultaneously experiencing a change in CEO lose almost half of their value between the initial and final announcements pertaining to these occurrences.

Mean cumulative prediction errors (CPEs) for accounting errors/ irregularities/method change for various intervals from 10 days before the announcement (day 0) through 1 day after the outcome is revealed (day $\mathrm{T}$ ) for a sample of restatement from 1994 to 1997.

Table 3: Accounting errors/ irregularities/method-change category

\begin{tabular}{|c|c|c|c|c|}
\hline Interval & $\mathbf{N}$ & Mean CPEs & $\mathbf{Z}$ & Proportion of positive observation \\
\hline$-10,0$ & 94 & -0.11241 & -9.975 & 30.85 \\
\hline
\end{tabular}




\begin{tabular}{|c|c|c|c|c|}
\hline$-5,0$ & 94 & -0.10505 & -12.736 & 29.79 \\
\hline$-1,0$ & 94 & -0.08436 & -18.181 & 27.66 \\
\hline$-2, \mathrm{~T}+1$ & 23 & -0.30462 & -9.559 & 13.04 \\
\hline
\end{tabular}

Mean cumulative prediction errors (CPEs) for accounting errors/ irregularities/method change for various intervals from 10 days before the announcement (day 0) through 1 day after the outcome is revealed (day $\mathrm{T}$ ) for a sample of restatement from 1994 to 1997.

Table 3a: Accounting errors/ irregularities/method-change confounded with CEO Resignation

\begin{tabular}{|c|c|c|c|c|}
\hline Interval & $\mathbf{N}$ & Mean CPEs & $\mathbf{Z}$ & Proportion of positive observation \\
\hline$-10,0$ & 14 & -0.37576 & -10.496 & 14.29 \\
\hline$-5,0$ & 14 & -0.31755 & -12.173 & 7.14 \\
\hline$-1,0$ & 14 & -0.22280 & -14.828 & 7.14 \\
\hline$-2, \mathrm{~T}+1$ & 5 & -0.48731 & -3.431 & 20.00 \\
\hline
\end{tabular}

\section{SEC Involvement}

Table 4 reports the mean cumulative prediction errors for the SEC involved category. The CPEs for the first three intervals $([-10,0],[-5,0],[-1,0]$, respectively) and associated test statistics are $-22.42 \%(Z=-5.71),-$ $15.33 \%(\mathrm{Z}=-5.73)$, and $-11.82 \%(\mathrm{Z}=-7.97)$. These are larger magnitude negative prediction errors than the overall sample and the accounting issues category. However, for the interval from day -2 to day $\mathrm{T}+1$, the mean cumulative prediction error is $16.10 \%$. For the 2 firms in this subset, there were material positive prediction errors from the initial "press" announcement to the final "resolution" announcement. However, this magnitude is not statistically significant $(Z=0.675)$. Nevertheless, this finding is consistent with the story that initially investors thought the SEC involved cases were very bad news, but as the uncertainty was resolved, it came to be considered that there had been an overreaction to the initial report of SEC involvement.

Mean cumulative prediction errors (CPEs) for SEC involved category for various intervals from 10 days before the announcement (day 0) through 1 day after the outcome is revealed (day $\mathrm{T}$ ) for a sample of restatement from 1994 to 1997.

Table 4: SEC involved

\begin{tabular}{|c|c|c|c|c|}
\hline Interval & $\mathbf{N}$ & Mean CPEs & $\mathbf{Z}$ & Proportion of positive observation \\
\hline$-10,0$ & 13 & -0.20417 & -5.751 & 23.08 \\
\hline$-5,0$ & 13 & -0.15332 & -5.733 & 15.38 \\
\hline$-1,0$ & 13 & -0.11816 & -7.970 & 38.46 \\
\hline$-2, \mathrm{~T}+1$ & 2 & 0.16097 & .675 & 50.00 \\
\hline
\end{tabular}

Fraud

Only 4 restatements were classified as reflecting overtly fraudulent activities. Findings for this small category are presented in Table 5. They present an interesting pattern. The first 2 intervals reported ([-10,0], [-5,0]) show mean prediction errors of approximately $20 \%$ and are approximately twice the negative magnitudes found for the overall sample. However, for the $(-1,0)$ interval the prediction errors are only $-6.20 \%$, raising the possibility that rumors were calibrating market expectations. The loss of approximately $20 \%$ in value with only $6.2 \%$ occurring with the formal announcement is consistent with the notion that the investigations associated with overt fraud had resulting in information pertaining to the upcoming restatement being conveyed to market participants before the formal announcement. 
Mean cumulative prediction errors (CPEs) for fraud category for various intervals from 10 days before the announcement (day 0) through 1 day after the outcome is revealed (day T) for a sample of restatement from 1994 to 1997.

Table 5: Fraud

\begin{tabular}{|c|c|c|c|c|}
\hline Interval & $\mathbf{n}$ & Mean CPEs & $\mathbf{Z}$ & Proportion of positive observation \\
\hline$-10,0$ & 4 & -0.19975 & -3.262 & 25.00 \\
\hline$-5,0$ & 4 & -0.21801 & -5.278 & 0.00 \\
\hline$-1,0$ & 4 & -0.06153 & -2.759 & 50.00 \\
\hline$-2, \mathrm{~T}+1$ & 0 & NA & NA & NA \\
\hline
\end{tabular}

\section{Restructuring}

As shown in Table 6, the mean prediction errors for restructuring are about only $1 / 3$ to $1 / 2$ of those of the overall sample and this is the category with the second smallest negative mean prediction errors. For the intervals ($5,0)$ and $(-1,0)$ the CPE prediction errors are $-5.43 \%$ and $-3.57 \%$. While these are statistically significant, the level of significance is materially lower than for most categories. Additionally, restructuring restatements have approximately a 50/50 proportion of positive observations.

Mean cumulative prediction errors (CPEs) for restructuring category for various intervals from 10 days before the announcement (day 0) through 1 day after the outcome is revealed (day T) for a sample of restatement from 1994 to 1997.

Table 6: Restructuring

\begin{tabular}{|c|c|c|c|c|}
\hline Interval & $\mathbf{N}$ & Mean CPEs & $\mathbf{Z}$ & Proportion of positive observation \\
\hline$-10,0$ & 15 & -0.04088 & -0.450 & 46.67 \\
\hline$-5,0$ & 15 & -0.05433 & -2.002 & 46.67 \\
\hline$-1,0$ & 15 & -0.03565 & -2.027 & 40.00 \\
\hline$-2, \mathrm{~T}+1$ & 0 & NA & NA & NA \\
\hline
\end{tabular}

With a restructuring, the fundamental business changes associated with restructuring have been previously announced and the accounting implications presumably estimated. It is not too surprising that the revaluation at the time of announcing the restated accounting numbers is of a relatively small magnitude. What may be considered surprising is that there is any significant reaction at that time.

\section{Legal Settlement}

There are two patterns of information release when legal settlements prompt the restatement. In some instances, the legal settlement itself has been announced prior to the publication of the associated restated accounting data (which reflects the financial implications of the settlement). Alternatively, the facts of the settlement and the restated numbers reporting its accounting implications are sometimes reported concurrently. Given the different patterns of information disclosure, we analyzed these two partitions of the Legal Settlement category separately.

\section{Settlement Prior to Restatement:}

There are 5 observations in the category of "legal settlement prior to restatement." A reasonable prior here is that the market may accurately anticipate the restatement (based on the facts previously released in the legal set- 
tlement announcement) and have no reaction to the restatement announcement itself. However, in contrast to that intuition, there is significant market reaction around the time of the earnings restatement. In fact, this is the only category with positive prediction errors around the time of the restatement announcement. These CPEs are $11.72 \%(\mathrm{Z}=$ $2.794)$ for the interval $(-10,0), 4.90 \%(Z=2.09)$ for the interval $(-5,0)$, as presented in Table $7 \mathrm{a}$. The mean cumulative prediction error over $(-1,0)$ is $-0.0004 \% \quad(Z=0.75)$. The majority of firms $(60 \%-100 \%$, depending on the specific interval) have positive prediction errors. On balance, the market interprets the restatement of accounting following the legal settlement announcement as good news. This suggests an area for further investigation, especially as the positive revaluations are in the longer intervals ending with the restatements, rather than the immediate $(-1,0)$ restatement window itself.

Mean cumulative prediction errors (CPEs) for legal settlement category for various intervals from 10 days before the announcement (day 0) through 1 day after the outcome is revealed (day $\mathrm{T}$ ) for a sample of restatement from 1994 to 1997.

Table 7a: Legal settlement prior to restatement

\begin{tabular}{|c|c|c|c|c|}
\hline Interval & $\mathbf{N}$ & Mean CPEs & $\mathbf{Z}$ & Proportion of positive observation \\
\hline$-10,0$ & 5 & 0.11716 & 2.794 & 100.00 \\
\hline$-5,0$ & 5 & 0.04904 & 2.090 & 60.00 \\
\hline$-1,0$ & 5 & -0.00035 & 0.745 & 60.00 \\
\hline$-2, \mathrm{~T}+1$ & 0 & NA & NA & NA \\
\hline
\end{tabular}

\section{Legal Settlement and Restatement Effects Announced Simultaneously:}

If the legal settlement and restatement are announced simultaneously, then as presented in Table 7b, the mean predict error is $-3.36 \%(Z=-1.93)$ and $-1.87 \%(Z=-1.70)$ for interval $(-5,0)$ and $(-1,0)$ respectively. The prediction errors are not statistically significant and are the smallest negative prediction errors among all categories. This is particularly notable in the context of positive reactions to restatements after the legal settlement had been previously announced. It underscores the potential for the legal settlement restatements to be the subject of additional research.

Mean cumulative prediction errors (CPEs) for legal settlement and restatement announced simultaneously for various intervals from 10 days before the announcement (day 0) through 1 day after the outcome is revealed (day T) for a sample of restatement from 1994 to 1997.

Table 7b: Legal settlement and restatement announced simultaneously

\begin{tabular}{|c|c|c|c|c|}
\hline Interval & $\mathbf{N}$ & Mean CPEs & $\mathbf{Z}$ & Proportion of positive observation \\
\hline$-10,0$ & 8 & -0.00659 & -0.274 & 50.00 \\
\hline$-5,0$ & 8 & -0.03355 & -1.929 & 12.50 \\
\hline$-1,0$ & 8 & -0.01868 & -1.696 & 12.50 \\
\hline$-2, \mathrm{~T}+1$ & 0 & NA & NA & NA \\
\hline
\end{tabular}

\section{Merger and Joint Venture Related Restatements}

We present the mean cumulative prediction errors of the merger/joint venture sub-sample in Table 8 . Given that these are restatements to reflect the accounting consequences of previously announced merger and JV activity, it seems reasonable to expect the market won't response significantly to the restatement announcement per se. Firms will have announced their plans to merger and form joint ventures before the restatement. Thus, once the original news has been released, it seems likely that efficient markets should anticipate the associated restatement of financial statements to make them comparable with previous reports. However, in contrast to these anticipations, there are significant negative CPEs associated with such restatements. The CPEs are $-10.30 \%(\mathrm{Z}=-3.829)$ over $(-$ 
$5,0)$ and $-5.45 \%(Z=-3.55)$ over $(-1,0)$, respectively. While the $Z$-scores are less than for several other categories of restatements, they are still significant at the $1 \%$ level.

Mean cumulative prediction errors(CPEs) for merging or joint venture and stock split/dividend categories for various intervals from 10 days before the announcement (day 0 ) through 1 day after the outcome is revealed (day T) for a sample of restatement from 1994 to 1997.

Table 8: Merger or Joint Venture

\begin{tabular}{|c|c|c|c|c|}
\hline Interval & $\mathbf{N}$ & Mean CPEs & $\mathbf{Z}$ & Proportion of positive observation \\
\hline$-10,0$ & 8 & -.11326 & -2.936 & 37.50 \\
\hline$-5,0$ & 8 & -.10239 & -3.829 & 37.50 \\
\hline$-1,0$ & 8 & -.05445 & -3.549 & 37.50 \\
\hline$-2, \mathrm{~T}+1$ & 0 & NA & NA & NA \\
\hline
\end{tabular}

\section{Conclusions}

This study provides the analysis of stock price changes associated with the announcement of accounting restatements. We find many reasons for such restatements, and identify 9 categories into which most restatements can be classified. Given that the sample firms are changing information previously released as having reported exposte data, these restatements have the potential to have a material impact on investors' evaluations of the restating firms. In turn, this recalibration of expectations regarding both the past results and the implications for expected future performance of these firms has the potential to affect their valuation. Empirically, we find material changes in valuations at the time of restatements, but the patterns vary across categories.

For overall sample, we find negative abnormal announcement-period returns over $(-1,0)$ of $8.77 \%$, and approximately $70 \%$ of the observations have negative prediction errors. $54 \%$ of the restatements are due to the accounting issues (errors/irregularities/method-changes), and cumulative prediction errors for this category are $8.44 \%$ at the immediate $(-1,0)$ restatement announcement. For other categories, the patterns of valuation consequences vary. In the case of restatements following previously announced legal settlements, the average valuation consequences are significantly positive. This legal settlement sub-sample is the only category with positive prediction errors and the majority of firms have positive CPEs.

The largest negative revaluations occur when accounting issues restatements are announced contemporaneously with the departure of a CEO. The negative prediction errors in these circumstances are approximately 3 times those for the overall sample. For the restructuring related restatement category, the mean cumulative prediction errors are about $1 / 3$ to $1 / 2$ of that of the overall sample, and the restructuring restatements have the second highest proportion of positive observations among all the categories. However, given that the restructuring events have been announced previously, it is somewhat surprising that there is any significant market reaction to the subsequently announced accounting manifestations of the previously disclosed changes. Similar reasoning applies to the merger and joint venture related prompted category, where the restatement calibrates previously announced corporate events.

Overall, the variation in valuation consequences across different categories of accounting restatements is substantial, and suggests that the informational content varies considerably. Although restatements are typically negative in nature, the extent to which they affect valuation has been seen to be impacted by the cause of and related context for the restatement.

\section{References}

1. American Institute of Certified Public Accountants, 1984, Statement on Auditing Standards No. 53, The Auditor's Responsibility to Detect and Report Errors and Irregularities. 
2. Benston, G.J., 1975, Accountant's integrity and financial reporting, Financial Executive, Aug., 10-14.

3. Bochus, K. and F. Gigler, 1995, Audit pricing, fraud, and resignation, Working paper, University of Chicago, Chicago, IL.

4. Bonner, Sarah E., Zoe-Vonna Palmrose, and Susan M.Young, 1998, Fraud type and auditor litigation: an analysis of SEC accounting and auditing enforcement releases, The Accounting Review 73, No. 4, 503-532.

5. Brumfield, C. A., R. K. Elliott, and P. D. Jacobson, 1983, Business risk and the audit process, Journal of Accountancy 155 (April), 60-68.

6. Dodd, Peter and Jerold B. Warner, 1983, on corporate governance: A study of proxy contests, Journal of Financial Economics 11, 401-438.

7. DeFond, Mark L. and James Jiambalvo, 1991, Incidence and circumstances of accounting errors, The Accounting Review 66, No. 3, 643-655.

8. _ $\quad$ and _ 1993, factors related to auditor-client disagreements over income-increasing accounting methods, Contemporary Accounting Research 9, No. 2, 415-431.

9. Francis, Jennifer, Donna Philbrick, and Katherine Schipper, 1994, Shareholder litigation and corporate disclosures, Journal of Accounting Research 32, No. 2, 137-164.

10. Hite, Gailen, and James Owers, 1983, Security price reactions around corporate Spin-off announcements, Journal of Financial Economics, 12, 609-636.

11. Hwang, Suein L., 1994, Marketing and media: Borden to reverse, reclassify $40 \%$ of 1992 charge, Wall Street Journal, 22 March.

12. Kellogg, R. L., 1984, Accounting activities, security prices, and class action suits, Journal of Accounting and Economics 3, 185-204.

13. Kinney, William R. and Linda S. McDaniel, 1989, Characteristics of firms correcting previously reported quarterly earnings, Journal of Accounting and Economics 11, 71-93.

14. _ and , 1993, Audit delay for firms correcting quarterly earnings, Auditing: A Journal of Practice \& Theory 12, No. 2, 135-142.

15. Kreutzfeldt, Richard W., and Wanda A. Wallace, 1986, Error characteristics in audit populations: their profile and relationship to environmental factors, Auditing: A Journal of Practice \& Theory 6, No. 1, 20-43.

16. Krishnan, Jagan and Jayanthi Krishnan, 1997, Litigation risk and auditor resignations, The Accounting Review 72, No.4, 539-560.

17. Meeks, Geoff, 1992, an accounting theory of merger, working paper, University of Cambridge.

18. Lys, T. and R. L. Watts, 1994, Lawsuits against auditors, Journal of Accounting Research 32 (Supplement), 65-93.

19. Palmrose, Z., 1988, an analysis of auditor litigation and audit service quality, The Accounting Review 63 (January), 55-73.

20. Pratt, Jamie and James D. Stice, 1994, The effects of client characteristics on auditor litigation risk judgments, required audit evidence, and recommended audit fees, The Accounting Review 69, N0. 4, 639-656.

21. Pulliam, Susan, and Lee Berton, 1994, heard on the street: a restructuring of write-offs is in the making, Wall Street Journal, 2 November.

22. Securities and Exchange Commission, 1979, Securities Act of 1933, Rel. No. 6084, Sec Docket 1048.

23. _ 1988, Financial Reporting Release No. 31, Commerce Clearing House, Chicago.

24. Siliciano, J. A., 1988, Negligent accounting and the limits of instrumental tort reform, Michigan Law Review_86 (August), 1929-1980.

25. St. Pierre, K., and J. Anderson, 1984, An analysis of the factors associated with lawsuits against public accountants, The Accounting Review 59, 242-263.

26. Stice, James D., 1991, Using financial and market information to identify pre-engagement factors associated with lawsuits against auditors, The Accounting Review 66 (July), 516-533.

27. Sullivan, J. D., 1992, Litigation risk broadly considered, In Auditing Symposium XI: Proceedings of the 1992 Deloitte \& Touche/University of Kansas Symposium on Auditing Problems, 49-59. University of Kansas, KS: School of Business.

28. Willingham, John J. and William F. Wright, 1985, Financial statement errors and internal control judgments, Auditing: A Journal of Practice \& Theory 5, No. 1, 57-70. 
Notes 


\section{Endnotes}

${ }^{\mathrm{i}}$ A prominent recent example was provided by Cendant Corporation, where the estimated amount of settlement relating to accounting irregularities was for a time a major factor in determination of the stock price. 
